\title{
Pharmacogenetic determinants of variability in lipid-lowering response to pravastatin therapy
}

\author{
Hiroshi Takane $\cdot$ Masanori Miyata $\cdot$ Naoto Burioka $\cdot$ \\ Chiaki Shigemasa $\cdot$ Eiji Shimizu $\cdot$ Kenji Otsubo $\cdot$ \\ Ichiro Ieiri
}

Received: 24 April 2006/ Accepted: 30 May 2006/Published online: 18 August 2006

(C) The Japan Society of Human Genetics and Springer-Verlag 2006

\begin{abstract}
Pravastatin is mainly taken up from the circulation into the liver via organic anion-transporting polypeptide 1B1 (SLCO1B1 gene product). We examined the contribution of genetic variants in the SLCO1B1 gene and other candidate genes to the variability of pravastatin efficacy in 33 hypercholesterolemic patients. In the initial phase of pravastatin treatment (8 weeks), heterozygous carriers of the $S L C O 1 B 1 * 15$ allele had poor low-density lipoprotein cholesterol (LDL-C) reduction relative to non-carriers (percent reduction: -14.1 vs $-28.9 \%$ ); however, the genotype-dependent difference in the cholesterol-lowering effect disappeared after 1 year of treatment. Cholesterol $7 \alpha$-hydroxylase $(C Y P 7 A 1)$ and apolipoprotein $\mathrm{E}(A P O E)$ are known to contribute to lipid metabolism. Homozygous carriers of the $C Y P 7 A 1$ 204C allele or heterozygotes for both $C Y P 7 A 1-204 \mathrm{C}$ and $A P O E \in 4$ alleles showed significantly poorer
\end{abstract}

H. Takane $\cdot$ K. Otsubo

Department of Hospital Pharmacy, Faculty of Medicine,

Tottori University, Yonago, Japan

M. Miyata $\cdot$ N. Burioka $\cdot$ E. Shimizu

Division of Medical Oncology and Molecular Respirology,

Faculty of Medicine, Tottori University, Yonago, Japan

C. Shigemasa

Division of Molecular Medicine and Therapeutics,

Department of Multidisciplinary Internal Medicine, Faculty

of Medicine, Tottori University, Yonago, Japan

I. Ieiri $(\bowtie)$

Department of Clinical Pharmacokinetics,

Graduate School of Pharmaceutical Sciences,

Kyushu University, 3-1-1, Maidashi, Higashi-ku,

Fukuoka 812-8582, Japan

e-mail: ieiri-ttr@umin.ac.jp
LDL-C reduction compared to that in other genotypic groups after 1 year of treatment $(-24.3$ vs $-33.1 \%)$. These results suggest that the $S L C O 1 B 1 * 15$ allele is associated with a slow response to pravastatin therapy, and the combined genotyping of $C Y P 7 A 1$ and $A P O E$ genes is a useful index of the lipid-lowering effect of pravastatin.

Keywords $S L C O 1 B 1 \cdot C Y P 7 A 1 \cdot A P O E \cdot$

Pravastatin $\cdot$ Cholesterol

\section{Introduction}

Coronary heart disease is the leading cause of death worldwide. Several risk factors for cardiovascular disease are well known, especially increased low-density lipoprotein cholesterol (LDL-C) and decreased highdensity lipoprotein cholesterol (HDL-C). Statins are inhibitors of 3-hydroxy-3-methylglutaryl coenzyme A (HMG-CoA) reductase, a rate-limiting enzyme in cholesterol biosynthesis. Lipid-lowering therapy by statins has the potential to improve outcomes in patients at risk for cardiovascular disease. Despite these large effects, interindividual variability in the response to statins has been observed in clinical situations (Pazzucconi et al. 1995). Previous studies have demonstrated that the mechanisms responsible for variability in the statin response are due, at least in part, to genetic factors. Most studies have focused on the association between variants $(\epsilon 2, \epsilon 3$ and $\epsilon 4)$ in apolipoprotein $\mathrm{E}(A P O E)$ gene, which is a primary ligand for the LDL receptor found on the liver, and the response to statins (Ojala et al. 1991; Ordovas et al. 1995). In addition, recent studies have demonstrated 
that variants in cholesterol 7alpha-hydroxylase (CYP7A1) (Pullinger et al. 2002), ABCG8 (Kajinami et al. 2004) and HMG-CoA reductase (HMGCR) (Chasman et al. 2004) are important determinants of the lipid response to statin therapy.

Pravastatin, a hydrophilic HMG-CoA reductase inhibitor, is taken up efficiently from the circulation into the liver by an active transport carrier system, but is not metabolized by CYP enzymes. Human organic anion-transporting polypeptide 1B1 (OATP1B1), transporter of pravastatin, is expressed on the basolateral membrane in the hepatocytes responsible for the hepatocellular uptake of pravastatin (Hsiang et al. 1999). The major site of cholesterol synthesis, the liver, is the main target organ of statins. Recently, Niemi et al. (2005) have shown that the SLCO1B1*17 allele (containing $-11187 \mathrm{G}>\mathrm{A}, 388 \mathrm{~A}>\mathrm{G}$ and $521 \mathrm{~T}>\mathrm{C}$ ) is associated with the decreased acute effect of pravastatin on cholesterol synthesis; however, the impact of $S L C O 1 B 1$ genotypes on the lipid-lowering response to pravastatin during long-term treatment has not been well investigated.

The aim of this study was to describe the influence of $S L C O 1 B 1$ genotypes on the lipid-lowering response to pravastatin in Japanese hypercholesterolemic patients. Furthermore, we evaluated the contribution of genetic variants in other candidate genes ( $A P O E$, $C Y P 7 A 1, A B C G 8$ and $H M G C R)$ to the variability in pravastatin efficacy.

\section{Materials and methods}

Study design

We studied 33 patients (14 males and 19 females; mean age 62.3 years; age range 34-83 years) with hypercholesterolemia treated in Tottori University Hospital. All subjects were initially prescribed pravastatin (mean dose range $9.4 \mathrm{mg} /$ day) between January 1997 and October 2004. We used the electronic medical database available in the hospital to obtain precise information on patients' backgrounds, laboratory tests, prescribed drugs and adverse events. We collected these data retrospectively for each patient for at least 1 year from the day pravastatin was administered. Patients with serious or uncontrolled renal or liver disease, no drug compliance, other hypolipidemic treatment or uncontrolled diabetes were excluded. The average body mass index (BMI), total cholesterol (TC) and LDL-C values in this study patients were $23.9 \mathrm{~kg} / \mathrm{m}^{2}$ (range $17.3-30.9 \mathrm{~kg} / \mathrm{m}^{2}$ ), $259.6 \mathrm{mg} / \mathrm{dl}$ (range $225.8-315.0 \mathrm{mg} / \mathrm{dl}$ ) and $167.4 \mathrm{mg} / \mathrm{dl}$ (range $112.0-240.7 \mathrm{mg} / \mathrm{dl}$ ), respectively. This study was approved by the Tottori University Ethics Committee, and informed consent was obtained from all individuals.

Genotyping

All subjects were genotyped for variants in the candidate genes involved in the pharmacokinetics and pharmacodynamics of pravastatin. Details of the genotyping and haplotyping of $S L C O 1 B 1^{*} 1 \mathrm{~b}$ $(388 \mathrm{~A}>\mathrm{G}), * 5 \quad(521 \mathrm{~T}>\mathrm{C})$ and $* 15 \quad(388 \mathrm{~A}>\mathrm{G}$ and $521 \mathrm{~T}>\mathrm{C}$ ) were described previously (Nishizato et al. $2003)$. The promoter variant $(-11187 \mathrm{G}>\mathrm{A})$ in the SLCO1B1 gene was determined with PCR-SSCP analysis. The $S L C O 1 B 1-11187 \mathrm{G}>\mathrm{A}$ variant was observed as heterozygosity $(0.212)$ in this patient group suggesting it was tightly linked to the SLCO1B1*15 allele. The genotypes in CYP7A1 $(-204 \mathrm{~A}>\mathrm{C})$ (Hubacek et al. 2003), $A P O E$ ( $\epsilon 2, \epsilon 3$ and $\epsilon 4)$ (Hixon and Vernier 1990) and $A B C G 8(55 \mathrm{G}>\mathrm{C})$ (Kajinami et al. 2004) were examined by previously described methods using PCR restriction fragment length polymorphism analysis. Genetic variants (SNP12 and 29) in the $H M G C R$ gene were found as functional variants for variable response to statin therapy in the previous study (Chasman et al. 2004) as determined with PCRSSCP analysis.

Statistical analysis

Comparisons between two groups were performed using a Student $t$-test and between more than two groups using ANOVA (with Tukey-Kramer multiple comparison test). A $5 \%$ level of probability was considered to be significant.

\section{Results and discussion}

The mean percent reductions from the baseline in TC and LDL-C values at 8 weeks post-treatment with pravastain were significantly smaller in heterozygous carriers of the $S L C O 1 B 1 * 15$ allele than in homozygous carriers of the $* 1 \mathrm{a}$ and $* 1 \mathrm{~b}$ alleles (Fig. $1 \mathrm{a}, P<0.05$ ). Also, the mean percent reduction from the baseline in TC values at 8 weeks post-treatment was significantly smaller in $S L C O 1 B 1^{*} 15$ carriers than in non-carriers ( -9.8 vs $-20.9 \% ; P<0.05$; Fig. 1 b). A similar trend was observed in the LDL-C level ( -14.1 vs $-28.9 \%, P<0.05$; Fig. 1b) even though the pravastatin daily dose (mean $\pm \mathrm{SD}$; non-carriers: $9.4 \pm 2.9 \mathrm{mg}$, carriers: 
(A)
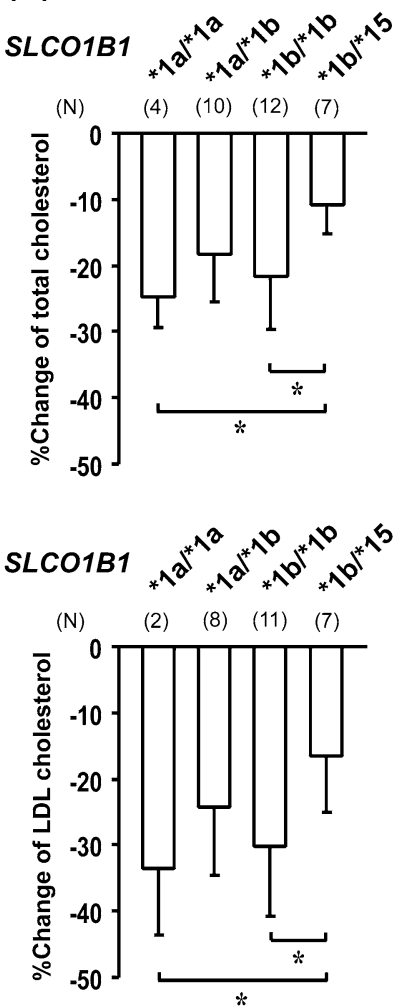

(B)
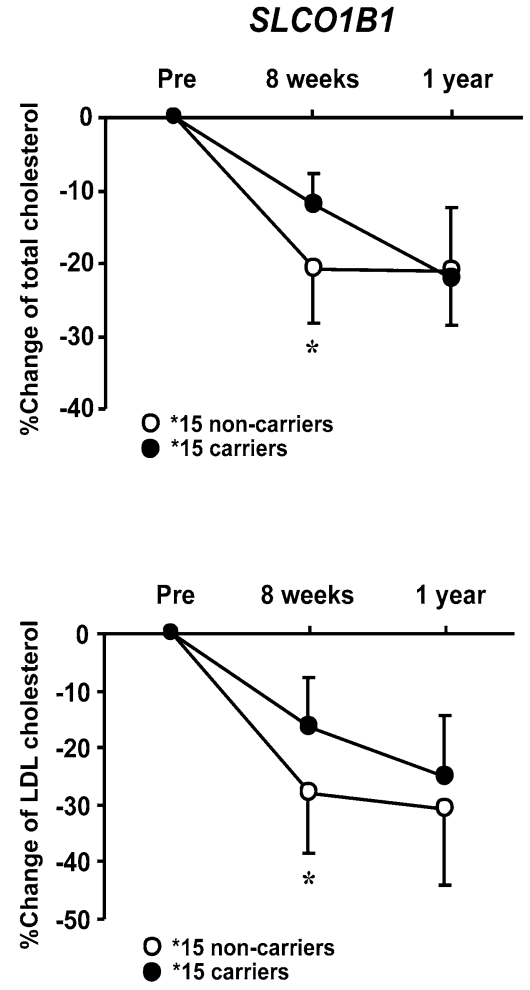

CYP7A1-APOE
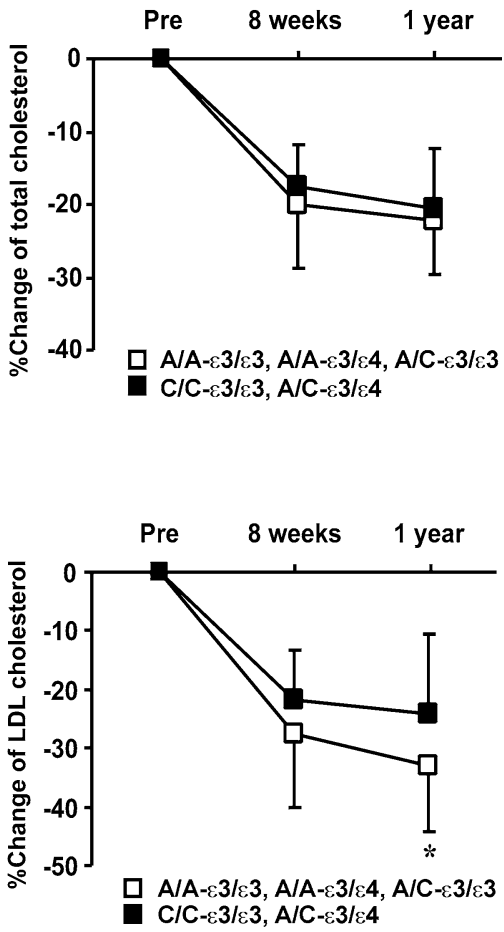

Fig. 1 a Influence of the $S L C O 1 B 1$ genotypes on percent reduction from baseline in TC and LDL-C values at 8 weeks after pravastatin treatment. $* P<0.05$ when compared between the two groups using Tukey-Kramer multiple comparison test. b Influence of the SLCO1B1, CYP7A1 and APOE genotypes on time course of percent reduction from baseline in TC and LDL$\mathrm{C}$ value after pravastatin treatment. ${ }^{*} P<0.05$ when compared between the two genotypes was analyzed with Student's $t$-test. Each value is the mean \pm SD

treatment. Although its mechanism remains to be elucidated, one possible reason is that all of our patients with the $S L C O 1 B 1 * 15$ allele were heterozygotes for functionally active $* 1$ a or $* 1$ b alleles (Iwai et al. 2004). Thus, the lipid-lowering profiles in homozygotes for the $* 15$ allele are of interest.

Multidrug resistance-associated protein 2 (MRP2/ ABCC2) on the bile canalicular membrane is mainly involved in the biliary excretion of pravastatin (Matsushima et al. 2005). With regard to liver concentration of pravastatin, genetic polymorphisms of MRP2 might affect response to pravastatin. However, $M R P 2$ variants have been observed at low frequency in Japanese (Itoda et al. 2002), and functional significance of these variants is not established. Therefore, association of MRP2 genotypes should be analyzed by further studies.

We also examined the influence of the CYP7A1 promoter $(-204 \mathrm{~A} / \mathrm{C})$ and $A P O E(\epsilon 2, \epsilon 3$ and $\epsilon 4)$ variants on the clinical outcome of pravastatin therapy. As shown in Fig. 1b and Table 1, the reduction from the baseline in LDL-C value at 1 year post-treatment was 
Table 1 Association of $S L C O 1 B 1, C Y P 7 A 1$ and $A P O E$ genotypes with lipid changes

\begin{tabular}{|c|c|c|c|c|c|c|c|}
\hline \multirow[t]{2}{*}{ Gene } & \multirow[t]{2}{*}{ Genotype } & \multicolumn{6}{|c|}{ Lipid concentrations (mg/dl) } \\
\hline & & $N$ & Baseline & $N$ & 8 weeks & $N$ & 1 year \\
\hline \multicolumn{8}{|l|}{ Total cholesterol } \\
\hline \multirow[t]{3}{*}{$S L C O 1 B 1 * 15$} & Non-carriers & 26 & $260.9 \pm 24.4$ & 26 & $205.8 \pm 22.2$ & 20 & $201.9 \pm 18.5$ \\
\hline & Carriers & 7 & $254.8 \pm 10.6$ & 7 & $227.9 \pm 19.6$ & 6 & $204.0 \pm 16.5$ \\
\hline & $P$ value & & NS & & $<0.05$ & & NS \\
\hline \multirow[t]{3}{*}{ CYP7A1-APOE } & $\mathrm{A} / \mathrm{A}-\epsilon 3 / \epsilon 3, \mathrm{~A} / \mathrm{A}-\epsilon 3 / \epsilon 4, \mathrm{~A} / \mathrm{C}-\epsilon 3 / \epsilon 3$ & 19 & $261.9 \pm 23.9$ & 19 & $210.3 \pm 27.9$ & 14 & $198.9 \pm 12.7$ \\
\hline & $\mathrm{C} / \mathrm{C}-\epsilon 3 / \epsilon 3, \mathrm{~A} / \mathrm{C}-\epsilon 3 / \epsilon 4$ & 14 & $256.4 \pm 20.1$ & 14 & $210.7 \pm 16.0$ & 12 & $206.0 \pm 22.3$ \\
\hline & $P$ value & & NS & & NS & & NS \\
\hline \multicolumn{8}{|l|}{ LDL cholesterol } \\
\hline \multirow[t]{3}{*}{$S L C O 1 B 1 * 15$} & Non-carriers & 22 & $170.7 \pm 27.4$ & 22 & $124.0 \pm 20.7$ & 17 & $115.1 \pm 23.9$ \\
\hline & Carriers & 7 & $157.0 \pm 29.3$ & 7 & $132.0 \pm 32.7$ & 6 & $110.5 \pm 10.9$ \\
\hline & $P$ value & & NS & & NS & & NS \\
\hline \multirow[t]{3}{*}{ CYP7A1-APOE } & $\mathrm{A} / \mathrm{A}-\epsilon 3 / \epsilon 3, \mathrm{~A} / \mathrm{A}-\epsilon 3 / \epsilon 4, \mathrm{~A} / \mathrm{C}-\epsilon 3 / \epsilon 3$ & 19 & $168.6 \pm 34.4$ & 19 & $124.0 \pm 29.9$ & 12 & $106.3 \pm 20.6$ \\
\hline & $\mathrm{C} / \mathrm{C}-\epsilon 3 / \epsilon 3, \mathrm{~A} / \mathrm{C}-\epsilon 3 / \epsilon 4$ & 12 & $165.7 \pm 16.3$ & 12 & $128.7 \pm 12.5$ & 10 & $123.8 \pm 12.5$ \\
\hline & $P$ value & & NS & & NS & & $<0.05$ \\
\hline
\end{tabular}

Values are mean \pm SD

Statistical significance between the two genotypes was analyzed with Student's $t$-test

NS No significant difference

significantly decreased in carriers of $\mathrm{A} / \mathrm{A}-\epsilon 3 / \epsilon 3, \mathrm{~A} / \mathrm{A}$ $\epsilon 3 / \epsilon 4$ or $\mathrm{A} / \mathrm{C}-\epsilon 3 / \epsilon 3$ in $C Y P 7 A 1$ and $A P O E$ genes compared with $\mathrm{C} / \mathrm{C}-\epsilon 3 / \epsilon 3$ or $\mathrm{A} / \mathrm{C}-\epsilon 3 / \epsilon 4$ carriers. There was no significant effect of genotypes (A/A- $\epsilon 3 / \epsilon 3, \mathrm{~A} / \mathrm{A}-\epsilon 3 /$ $\epsilon 4$ or $\mathrm{A} / \mathrm{C}-\epsilon 3 / \epsilon 3$ vs $\mathrm{C} / \mathrm{C}-\epsilon 3 / \epsilon 3$ or $\mathrm{A} / \mathrm{C}-\epsilon 3 / \epsilon 4)$ in the $C Y P 7 A 1$ and $A P O E$ genes on pravastatin dose $(10.0 \pm 2.9$ vs $8.8 \pm 2.9 \mathrm{mg})$ and BMI $(23.8 \pm 3.6$ vs $24.5 \pm 3.0 \mathrm{~kg} / \mathrm{m}^{2}$ ). Only one patient was a heterozygous carrier of SNP12 in the HMGCR gene. However, no remarkable difference in the lipid-lowering effects was observed in this patient. Also, SNP29 in HMGCR and $55 \mathrm{G}>\mathrm{C}$ in $A B C G 8$ were not detected.

In contrast to $S L C O 1 B 1$ gene, part of the interpatient variability in the efficacy of pravastatin after longterm treatment may be attributable to genetic variation, and combined genotyping of $C Y P 7 A 1$ and $A P O E$ genes is useful for describing the lowering effects. Since the basal cholesterol synthesis rate is a key determinant for statin response, loss of CYP7A1 activity, which is involved in bile acid synthesis from cholesterol in the liver, may result in a poor response to statin treatment (Pullinger et al. 2002). A previous study has shown that the nucleotide sequence around position 204 negatively regulates CYP7A1 promoter activity (Cooper et al. 1997). Among the known variants, the CYP7A1 $-204 \mathrm{~A}>\mathrm{C}$ variant is expected to decrease promoter activity (Kajinami et al. 2005). Apolipoprotein $\mathrm{E}$ is known as one of the major determinants in lipoprotein metabolism. Previous studies (Ojala et al. 1991; Ordovas et al. 1995) demonstrated that the $\epsilon 4$ allele in primary hypercholesterolemia is associated with lower response to statin, when compared to $\epsilon 2$ and $\epsilon 3$ alleles, because the binding activity of $\epsilon 4$ allele to receptor is relatively higher than that of other alleles. These results suggest that decreased cholesterol 7alpha-hydroxylase activity and increased binding affinity of apolipoprotein E to LDL receptor enhance the intracellular cholesterol content in hepatocytes, resulting in lower HMG-CoA reductase activity, which may also lead to tolerance to statin treatment (Kajinami et al. 2005).

In conclusion, our results suggest that the $S L C O 1 B 1 * 15$ allele is associated with a slow response to pravastatin. Instead of $S L C O 1 B 1^{*} 15$, combined genotyping of $C Y P 7 A 1-204 \mathrm{~A}>\mathrm{C}$ and $A P O E \in 4$ variants may be useful for describing the long-term clinical outcomes of pravastatin. Further study is necessary to confirm the influence of genetic variants in these candidate genes on the lipid-lowering efficacy of pravastatin as well as other statins in a large sample size.

Acknowledgements This study is supported by Health and Labor Sciences Research Grants from the Ministry of Health, Labor and Welfare, Tokyo, Japan.

\section{References}

Chasman DI, Posada D, Subrahmanyan L, Cook NR, Stanton VP, Ridker PM (2004) Pharmacogenetic study of statin therapy and cholesterol reduction. JAMA 291:2821-2827

Cooper AD, Chen J, Botelho-Yetkinler MJ, Cao Y, Taniguchi T, Levy-Wilson B (1997) Characterization of hepatic-specific regulatory elements in the promoter region of the human cholesterol 7alpha-hydroxylase gene. J Biol Chem 272:34443452

Hixon JE, Vernier DT (1990) Restriction isotyping of human apolipoprotein E by gene amplification and cleavage with HhaI. J Lipid Res 31:545-548 
Hsiang B, Zhu Y, Wang Z, Wu Y, Sasseville V, Yang WP, Kirchgessner TG (1999) A novel human hepatic organic anion transporting polypeptide (OATP2). J Biol Chem 274:37161-37168

Hubacek JA, Pitha J, Skodova Z, Poledne R, Lanska V, Waterworth DM, Humphries SE, Talmud PJ (2003) Czech MONICA Study. Polymorphisms in CYP7A1, not APOE, influence the change in plasma lipids in response to population dietary change in an 8 year follow-up; results from the Czech MONICA study. Clin Biochem 36:263-267

Itoda M, Saito Y, Soyama A, Saeki M, Murayama N, Ishida S, Sai K, Nagano M, Suzuki H, Sugiyama Y, Ozawa S, Sawada J (2002) Polymorphisms in the ABCC2 (cMOAT/MRP2) gene found in 72 established cell lines derived from Japanese individuals: an association between single nucleotide polymorphisms in the 5'-untranslated region and exon 28. Drug Metab Dispos 30:363-364

Iwai M, Suzuki H, Ieiri I, Otsubo K, Sugiyama Y (2004) Functional analysis of single nucleotide polymorphisms of hepatic organic anion transporter OATP1B1 (OATP-C). Pharmacogenetics 14:749-757

Kajinami K, Brousseau ME, Nartsupha C, Ordovas JM, Schaefer EJ (2004) ATP binding cassette transporter G5 and G8 genotypes and plasma lipoprotein levels before and after treatment with atorvastatin. J Lipid Res 45:653-656

Kajinami K, Brousseau ME, Ordovas JM, Schaefer EJ (2005) A promoter polymorphism in cholesterol $7 \alpha$ a-hydroxylase interacts with apolipoprotein E genotype in the LDL-lowering response to atorvastatin. Atherosclerosis 180:407-415

Matsushima S, Maeda K, Kondo C, Hirano M, Sasaki M, Suzuki H, Sugiyama Y (2005) Identification of the hepatic efflux transporters of organic anions using double-transfected Madin-Darby canine kidney II cells expressing human organic anion-transporting polypeptide 1B1 (OATP1B1)/ multidrug resistance-associated protein 2, OATP1B1/multidrug resistance 1 , and OATP1B1/breast cancer resistance protein. J Pharmacol Exp Ther 314:1059-1067

Niemi M, Neuvonen PJ, Hofmann U, Backman JT, Schwab M, Lutjohann D, von Bergmann K, Eichelbaum M, Kivisto KT (2005) Acute effects of pravastatin on cholesterol synthesis are associated with SLCO1B1 (encoding OATP1B1) haplotype*17. Pharmacogenet Genomics 15:303-309

Nishizato Y Nishizato, Ieiri I, Suzuki H, Kimura M, Kawabata K, Hirota T, Takane H, Irie S, Kusuhara H, Urasaki Y, Urae A, Higuchi S, Otsubo K, Sugiyama Y (2003) Polymorphisms of OATP-C (SLC21A6) and OAT3 (SLC22A8) genes: consequences for pravastatin pharmacokinetics. Clin Pharmacol Ther 73:554-565

Ojala JP, Helve E, Ehnholm C, Aalto-Setala K, Kontula KK, Tikkanen MJ (1991) Effect of apolipoprotein E polymorphism and XbaI polymorphism of apolipoprotein $\mathrm{B}$ on response to lovastatin treatment in familial and non-familial hypercholesterolaemia. J Intern Med 230:397-405

Ordovas JM, Lopez-Miranda J, Perez-Jimenez F, Rodriguez C, Park JS, Cole T, Schaefer EJ (1995) Effect of apolipoprotein $\mathrm{E}$ and A-IV phenotypes on the low density lipoprotein HMG CoA reductase inhibitor therapy. Atherosclerosis 113:157-166

Pazzucconi F, Dorigotti F, Gianfranceschi G, Campagnoli G, Sirtori M, Franceschini G, Sirtori CR (1995) Therapy with HMG CoA reductase inhibitors: characteristics of the longterm permanence of hypocholesterolemic activity. Atherosclerosis 117:189-198

Pullinger CR, Eng C, Salen G, Shefer S, Batta AK, Erickson SK, Verhagen A, Rivera CR, Mulvihill SJ, Malloy MJ, Kane JP (2002) Human cholesterol $7 \alpha$-hydroxylase (CYP7A1) deficiency has a hypercholesterolemic phenotype. J Clin Invest 110:109-117 